\title{
O processo de globalização e as perspectivas emergentes para a educação fisica
}

Patrícia Corrêa*

\section{Resumo}

A preocupação neste artigo, será apresentar um esboço, uma discussão, sobre a influência da globalização no mundo, no Brasil e de certa Forma na Educação Física, enfatizando pontos concernentes à sua intervenção social, inclusive no mercado atua de nossa profissão.

\section{Abstract}

The preocupation in this leading, whe to present an discusion at the influence of globalizacion of wolrd, to Brazil and of in a way, in breading physical, entevention social, inclusively the market of work present of our profession.

O termo globalização muito em voga nos dias de hoje, é um processo que vem ocorrendo a várias décadas; consubstanciando-se com as grandes transformações políticas e sociais que ocorreram no mundo $\left(1^{\mathrm{a}}\right.$ Guerra mundial, $2^{\mathrm{a}}$ guerra mundial, a guerra fria, a queda do muro de Berlim etc.). Podemos afirmar que a globalização faz parte de ajustes económicos sociais e políticos do sistema capitalista que se alastrou por todo o universo, desde o seu início na Europa Ocidental no século XVIII. até nossos dias com fato inexorável e universal. Nessa perspectiva, concordamos com o autor que explicita que:

"É claro que a globalização das sociedades, em curso nesta altura da história, vinha ocorrendo em décadas e séculos anteriores. O capitalismo com o qual nasce o mundo de que falamos no século XX, é um modo de produção e reprodução material e espiritual que se forma, expande e transforma em moldes internacionais" (lanni, 1993:36).
Nos tempos atuais tudo está em fase de aceleração capitalista, num ritmo jamais visto ou percebido tão claramente, em que o produtor vai comprar matéria-prima em qualquer lugar do mundo onde ela esteja mais barata e de melhor qualidade. Instala a fábrica nos países onde a mãode-obra esteja mais em conta, é claro que primando para o exército de reservas destes países, não importando se é no Vietnã ou na Guatemala. Vende mercadoria para o mundo todo numa relação de trocas mercantis. Em resumo o contínuo avanço da produção tecnológica, o aumento maior da produtividade, a exigência para se vender mercadorias, fazem com que sejam novos mercados novas fronteiras em várias partes do mundo. E é esta a nova ordem mundial que está em andamento, à beira do século XXI.

\section{E O BRASIL ONDE FICA}

Todas as transformações inerentes a globalização, produziram modificações em tal profundidade que ainda é difícil avaliar todos os aspectos deste fenómeno. Sabemos que os países precisam ajustar-se para permanecer competitivos numa economia global. Em conseqüência desse processo, advém a grande problemática do Brasil, enquanto país subdesenvolvido, industrializado do terceiro mundo, sofrendo influência dos países dominantes que atuam em suas decisões de modo imperialista-civilizatório, em concordância ao interesses deles. De acordo com lanni (1993) tais exigências ocorrem via organizações económicas, políticas, culturais e sociais que exercem missões civilizatórias nos países menos desenvolvidos, atrasados, periféricos do terceiro mundo. Tais missões são implementadas pelos organismos multinacionais como o Banco Mundial e Fundo Monetário Internacional (FMI), instituições que formalmente são produtos das alianças entre estados, mas de fato funcionam segundo a lógica do capitalismo internacional de dominação. Desta forma, o 
neoliberalismo passa a ser um dos principais instrumentos da prática económica do Brasil. Alguns movimentos da América Latina surgiram em relação a esta nova demanda mundial como por exemplo, o Pacto Andino e o Mercosul, todavia a movimentação comercial desses blocos passa a uma grande distância dos principais blocos (NAFTA, CEE)

O que observamos hoje no Brasil é um estado sem fundo para investir e as corporações com o dinheiro saindo pela janela (dinheiro volátil), tendo como "solução": ideológica ou não a privatizacão. Os governos vendem usinas, estradas e serviços porque não tem mais dinheiro para bancar investimentos nesses setores e o setor privado supostamente têm, diante desse ponto de vista, faz-se a seguinte indagação.

Quais seriam as vantagens e desvantagens desse novo modelo de mundo, da globalização? Poderíamos enumerar muitos contudo:

"O que a modernização, a indústria e a cidade ainda não trouxeram para os nossos países da América Latina foi a extinção da miséria, a saúde do povo, a felicidade da criança, a justiça social" (Albornoz, 1994:30).

É possível uma solução para essa problemática? Acreditamos que interrogação é que não falta concernente ao futuro imediato do Brasil. Porém poderíamos dar um passo seguro que seria investir na Educação, no sentido de formar indivíduos qualificados para o mundo tecnológico do século XXI, entretanto é deprimente sabermos que não há investimentos suficiente neste setor e total ausência de urna política que garanta ao país, qualidade e quantidade de cérebros preparados para o mundo competitivo de hoje.

Alguns cientistas e pesquisadores renomados da UFRJ como: Alberto Luiz Coimbra, Clementino Fraga Filho, Leopoldo de Méis..., publicaram um documento/ manifesto em repúdio ao descaso do governo (cadernos do Terceiro Mundo, 195, 1996 : 12). Para muitos "um país que não prioriza a educação, a ciência e a tecnologia, não terá autonomia para decidir sobre seu destino e estará condenado a posições cada vez mais subalternos na comunidade das nações (idem). Mas como romper com as fronteiras de domínio tecnológico? Sabemos que é difícil nos equiparar com as grandes nações do mundo, mas precisamos correr atrás do prejuízo e tentar nos adequar a este novo modo de mundo emergente, já que não podemos reverter este processo, nesta altura da história.

\section{A EDUCAÇão FíSICA E A GLOBALIZAÇÃo}

A Educação Física neste processo de globalização, no seu lado mais abrangente, explicito, atua como um bem de consumo, principalmente levando em consideração a vertente da cultura corporal-esportiva especializada (esporte de alto nível) que nada mais é do que mercadoria. Uma mercadoria como outra qualquer onde o lucro está sempre em primeiro plano. Muitas vezes nesse lado esportivo há ausência de caráter crítico-esclarecedor. onde professores, técnicos, treinadores etc... repassam valores e normas da sociedade capitalista de produção, não podendo ser diferentes enquanto esses "valores incutidos" mantiverem os ditames da supervalorização comercial.

Para intensificar ainda mais o consumo, entra em cena, os meios de comunicação, a mídia como um processo altamente persuasivo, dominador e alienante, conseguindo ocupar um campo de entretenimento que atrai uma massa de público considerável, principalmente a televisão que através das transmissões de torneios, campeonatos, olimpíadas, etc.., exibem um show de cores e imagens, efeitos especiais que encantam, divertem, prendem a atenção do público sendo um dos melhores meios para atrair as massas, implementando uma indústria cultural manipulativa. Esta "indústria cultural" promove uma homogeneização do pensamento, levando as mesmas notícias, as mesmas mensagens para os quatros cantos do mundo. Fornecendo explicações, lançando necessidades, prometendo realizações pessoais. Transformando atletas em corpo mercador e mercadorias das grandes empresas esportivas, que ostentam suas marcas com orgulho, como indicativo de melhor performance atlética, estabelecendo a permanência do corpo produtivo, apolitico e acrílico. Por tudo isso é que houve uma proliferação de academias de ginástica e um aumento substancial de produtos e cosméticos de beleza transformando o ser humano num mero "consumidor - freguês" sem ao menos este tomar consciência disso. Nós profissionais de Educação Física, deveríamos tomar consciência desse fato, afinal somos uma parte da sociedade melhor esclarecida (Pressupõe-se devido a uma vida académica progressiva $1^{\circ}, 2^{\circ}$ e $3^{\circ}$ grau) e consequente com melhores chances de interpretar a patranha dominante, tomar posição e agir contra ela (Ketler, 1992), dando oportunidade de discernimento ao indivíduo, mediante a demanda de mercadorias que lhe são ofertadas.

$\mathrm{O}$ avanço da tecnologia e a descoberta quase que diária de novas invenções e aparelhos, fazem com que 
sejam abertos novos serviços, novos mercados, para suprir as necessidades que surgem no dia-a-dia, poderíamos inter-relacionar, no campo da Educação Física, alguns mercados versus modalidades emergentes, resultante desse processo.

Como novos mercados teríamos o PERSONAL TRAINING (muito em voga devido a comodidade e resultados rápidos, estando também por trás a questão ideológica ); Educação Física nas empresas: ENDOMARKETING (tendo objetivos dicotômicos, promovendo o bem estar do empregado e com certeza o aumento da produtividade); EMPREENDIMENTOS DE LAZER, TURISMO, HOTÉIS E EXCURSÕES (principalmente através de atividades que envolva a natureza. A preocupação ambiental passou a ser vista como dimensões interdisciplinares e não apenas como ecologia); e outras. Quanto as modalidades tendo impulsão, principalmente por parte de interesses econômicos que através do consumo dos próprios equipamentos, de uma forma rentável tem promovido o aparecimento e intensificação de modalidades ricas em emoções, alto custo e alto risco como: Voo livre, Wind-surf, surf, Body bord, Jetsky, etc.. Cujo acervo cresce a cada temporada de férias ou verão pelas suas características ganham a efetividade necessária para o seu sucesso (Tubino, 1992). É claro que todas essas novas formas de atividade são privilégios de uma determinada classe social, em detrimento de outra que não tem nem acesso a uma efetiva prática de esportes.

A guisa de conclusão, para um profissional se adequar a este novo paradigma a esta nova realidade é necessário que haja uma reorganização, forçando estes "profissionais" a um penoso processo de aprendizagem que vai desde a formação académica até sua atuação permanente no mercado de trabalho, passando pela Pós-Graduação, pela literatura especializada e participação em eventos técnicos científicos, abrangendo uma área bem mais ampla que o ensino, com perspectivas de transformações mais dinâmicas e aceleradas.

\footnotetext{
"O processo de formação profissional não termina na Universidade. Uma profissão não deve apenas colocar em prática de forma socialmente útil os conhecimentos existentes, mas ser capaz de absorver novos conhecimentos, na medida que se tornam disponíveis na disciplina académica, modificando e aperfeiçoando sua prática" (Mauro Betti, 1993: 240-1).
}

Então o que estamos esperando para colocar-nos numa postura de profissional qualificado, conscientizado e preparado para estas novas mudanças, para esses novos paradigmas que estão ocorrendo na realidade da Educação Física e do mundo. Sabemos que é um enorme desafio, todavia há perspectiva de solução.

\section{REFERÊNCIAS BIBLIOGRÁFICAS}

ALBORNOZ, Suzana. O que é trabalho 6.ed. São Paulo: Brasiliense, 1994.

UM GRITO PELA CIÊNCIA. Cadernos do Terceiro Mundo. São Paulo: v.195, p.12-3, Jun/jul, 1992.

B ARROS, J. M. C. Educação Física: Perspectivas e tendências na profissão. Motriz. Rio Claro, n.1, p.49-51, JUN. 1996.

BETTI, ICR; BETTI, M. Novas perspectivas na formação do profissional em Educação Física. Motriz. Rio Claro, v.2, n.1,p.1O-15,jun. 1996.

CONTURSI, B.E. O novo profissional de Educação Física no mercado de negócios. Sprint. Rio de Janeiro, n.80, p.4950, 1995 .

CORRÊA, P. Educação Física, Esporte e a Nova Ordem Mundial. Sprint. Rio de Janeiro, p.20-21, set/out. 1998.

DAUDT, N. e RODRIGUES, L. Universidade ou "university" Cadernos do terceiro mundo, v.192, p.191-2, 1995.

IANNI, O. A sociedade global. 2.ed. Rio de Janeiro: ed. Civilização Brasileira, 1993.

KETLER, E. Educação: Crise e mudança. Sprint. Rio de Janeiro, n.48, p.50, mai/jun, 1992.

MACEDO, L. Educação Física: Novos mercados de trabalho. Sprint. Rio de Janeiro, n.84, p.20-21, mai/jun, 1996.

MOREIRA, Wagner, org. Educação Física e espanes: Perspectivas para o século XXL Campinas: Papirus. 1993.

TUBINO, M. J. G. As dimensões sociais do esporte. São Paulo: Cortez: Autores associados, 1992.

\section{UNITERMOS}

Globalização; avanço tecnológico; nova ordem mundial

* Patrícia Corrêa é professora responsável do polo esportivo SEDUC/PA, Pós-Graduada em Treinamento Desportivo na Infância e Adolescência /UEPA. 